\title{
Mi primera lectura académica: Mimesis, de Erich Auerbach'
}

\author{
My First Academic Lecture: Mimesis by Erich Auerbach
}

\author{
OTTMAR ETTE \\ Universidad de Postdam \\ Alemania \\ ette@uni-potsdam.de
}

(Recibido: 24/05/2020; aceptado: $26 / 05 / 2020$ )

Me siento en un banco al sol en el patio de la universidad de Freiburg y leo mi primer libro académico. La Selva Negra trae un viento fresco. Ya no sé cuánto tiempo leí este libro en ese lugar y hasta qué capítulo llegué, pero siento muy bien lo soleada que estaba aquella tarde de octubre y que no puedo olvidar aquellas horas, porque fue un descubrimiento, un viaje de aventura que comenzó allí y todavía está presente².

Leía a Erich Auerbach, en concreto Mimesis, en una edición barata para estudiantes, en formato pequeño, con letras minúsculas, un libro grueso que todavía hoy consulto y que no quiero leer en ninguna otra edición. En ese momento, cuando empecé a estudiar, no sabía mucho de Romanística y todavía menos de Erich Auerbach, que escribió su trabajo principal en el exilio de Estambul, entre 1942 y 1945, tal y como supe a través de una noticia que leí antes de leer su libro.

Abro la primera página del libro y de golpe estoy ahí. Sin prólogo que te avise, tampoco sin introducción: desde la primera línea te metes justo en medio de la acción; es el "lector de la Odisea" del que habla Auerbach en las primeras líneas. Había leído $L a$ Odisea en el liceo y me sentí interpelado: Conocía la escena, sí. Y la odisea de este libro, el viaje de aventuras de este volumen, pudo ser el comienzo -hasta que, mucho más tarde, se produce ese retorno feliz, en las últimas páginas del libro- de una "comunidad de lectores” en la que finalmente me sentí incluido. Con Auerbach, la Romanística se convirtió en mi especialidad.

\footnotetext{
${ }^{\text {I }}$ Para citar este artículo: Ette, Ottmar (2020). Mi primera lectura académica: Mimesis, de Erich Auerbach. Álabe 22 . [www.revistaalabe.com] DOI: IO.I5645/Alabe2O2O.22.I3

${ }^{2}$ La traducción del original alemán al español ha sido realizada por A. Daniel Fuentes González.
} 
Mimesis cuenta una historia que atraviesa la literatura occidental, desde la antigüedad hasta (casi) el día de hoy. Esa fue la primera sorpresa. Comencé a entender que la Romanística no se contentaba con estudiar francés, italiano o español, sino que la Romanística lo es verdaderamente si vas mucho más allá de todo ello, de la Romanística misma. Largos capítulos surcaban la antigüedad y la tardoantigüedad, hasta que llegué al periodo medieval de las literaturas románicas y, en el octavo de los veinte capítulos, encontré a Dante y su desarrollo de la lengua vernácula italiana, del volgare illustre. El volumen me dejó claro que estaba haciendo un curso de gran profundidad histórica y que el presente solo se hace presente a través de la riqueza del pasado.

Ahora hojeo los primeros capítulos y noto que entre estos hay grandes espacios vacíos. Auerbach no había escrito de forma continua, sino en fracciones y en discontinuidades. Y, sin embargo, contó una historia en toda su amplitud. Veo que los capítulos pasan volando y no siempre establecen relaciones directas entre capítulos sucesivos. No fue hasta mucho después cuando supe que Auerbach escribió en islas, que todo su libro es un archipiélago de capítulos construidos y conectados directamente como islas.

El libro está precedido por la frase "Escrito entre mayo de I942 y abril de I945", sin comentario alguno. Esta fue una indicación importante que me permitió leer el libro no solo como una historia, sino también como historia. Como una historia autobiográfica, en concreto. Porque Mimesis cuenta y oculta, casi con timidez, la historia de un exiliado que, como Odiseo, tuvo su cicatriz, que fue arrojado al espacio de la Odisea en esos años: como refugiado entre dos mundos, Europa y Asia, como un romanista alemán en el exilio turco, como filólogo judío en una zona fronteriza del mundo occidental, de cuya literatura trata su libro.

Salto de capítulo en capítulo, de isla en isla. Más tarde, debería visitar la casa de Auerbach en el Bósforo, llegar a esas islas cercanas donde, desde la distancia, todavía se puede ver el área urbana de Estambul. Me conmovió saber que Erich Auerbach había hecho un viaje de isla en isla a través del Egeo en el mismo año I938, cuando el escritor y teórico francés Roland Barthes se dirigía al mundo de las islas griegas, el Barthes sobre el que iba a habilitarme. Comprendí que los capítulos individuales estaban interrelacionados, y que con Mimesis no solo tenía un libro académico, sino también una pieza literaria de la que disfrutaba literariamente.

Leo y leo, con la seguridad de que no lo estaba entendiendo todo. ¿Y para qué? Porque leo con la alegría que te atrapa cuando lees buena literatura y te enseñan un saber de la vida para la vida. Leí con la curiosidad con la que más tarde devoré las grandes obras académicas, pero al mismo tiempo leí con esa ingenuidad naíf desde la que todavía no podía saber nada sobre esa historia de la Romanística alemana que sentí como parte de una historia alemana (Nunca dejaría esa ingenuidad desde mi primer intercambio escolar en Francia, cuando tenía II o I2 años). Se convirtió en la historia de un alemán atrapado en la historia alemana, la historia que había llevado a Auerbach al exilio, historia de persecución, asesinato y genocidio, que en este libro cuenta la historia entre líneas, entre capítulos, entre islas. 
Leí el capítulo catorce, “La Dulcinea encantada”, y me enteré de que Erich Auerbach lo añadió más tarde, en I949. Auerbach no era hispanista, su especialidad eran otras literaturas, pero sintió y también se le informó de que su libro no podría funcionar sin Cervantes y sin su Don Quïote. Cervantes, sobre quien su alumno Werner Krauss había investigado tanto, ese alumno y sucesor de Auerbach en Marburg que luego luchó en la resistencia contra Hitler, fue condenado a muerte, escribió un libro sobre Baltasar Gracián y una maravillosa novela en el corredor de la muerte; al final, con una felicidad indescriptible, sobrevivió. Erich Auerbach fundó una tradición de la Romanística alemana, una tradición de resistencia, que siempre ha sido minoritaria frente a la otra tradición creada después de la guerra por un ex oficial de alto rango de las Waffen SS. Pero no pude saber todo eso en aquel momento.

Las hojas del libro vuelan y vuelan, bañadas por el sol en el patio interior, que todavía te permite sentir un poco el sol que iluminó a Auerbach en el Bósforo. ¿Cómo pudo haber escrito este libro, lejos de sus queridas bibliotecas de Marburg y de Berlín? Incluso en ausencia de una biblioteca especializada, el exiliado escribió y escribe la persecución en cada línea y entre todas las líneas de este libro. Por eso no se convirtió en un libro puramente académico, sino en un libro autobiográfico, literario, orquestado por muchas voces y con muchas lógicas. Instintivamente entendí que un libro filológico también podía ser literatura Dera la verdadera razón de mis estudios-, sin tener que renunciar a todas las ventajas que me entusiasmaban de la literatura. Fue la lengua de la literatura lo que hizo de este libro algo grandioso, algo que fue mucho más allá de su tiempo y sigue siendo un impulso inigualable.

Por la noche, junto a la estufa de gasoil de mi piso de estudiantes, leí los últimos capítulos de Mimesis. Ese pequeño gran libro me acompañó durante el primer mes de mi carrera de Románicas. Todavía me acompaña en mi camino a través de la Romania y aun más allá. Erich Auerbach, como ya escribió en el título, escribió un libro sobre literatura occidental. Aunque más tarde reemplazó su exilio en Turquía no con una fallida vuelta a Alemania, sino con sus años en los Estados Unidos de América, nunca escribió sobre literatura románica en el continente americano. En los estudios de Romanística alemana en los que se formó Erich Auerbach no había América Latina, ni tampoco literatura española, portuguesa o francesa del "Nuevo Mundo". Permanecieron fuera del horizonte de Auerbach.

Al final de Mimesis, Auerbach se dirige a todos esos lectores "que han mantenido el amor por nuestra historia occidental sin obnubilarse”. Estas son las últimas palabras de un libro que, tras sus más de quinientas páginas, tiene un final que puede sorprender en un volumen filológico: el del amor. En medio de una situación de exilio, de persecución, de la amenaza más profunda, Auerbach encuentra el antídoto que se opone a todo el odio que lo persiguió, incluso después de la caída de la Alemania nazi. Es ese amor presente en el concepto de filología, el amor por las palabras y los objetos que debería caracterizar la actividad filológica, pero al mismo tiempo es algo más: un amor por las personas que se demuestra en ese maravilloso libro tan abierto y tan alegre, totalmente contrapuesto 
a la oscuridad de su tiempo. En mi escritorio, la frase de José Martí sobre la que estaba haciendo mi doctorado: "No se canse de amar, no se canse de amar nunca".

Leo en Mimesis de Erich Auerbach y deslizo el grueso pero discreto volumen entre los dedos. Nunca me canso de leerlo, de vivir en este volumen. Para encontrar fuerza en el amor que hay en el corazón de cada lectura detenida y emocionada. 